\title{
ClearPath-assisted underwater endoscopic mucosal resection of a laterally spreading tumor of the colon
}
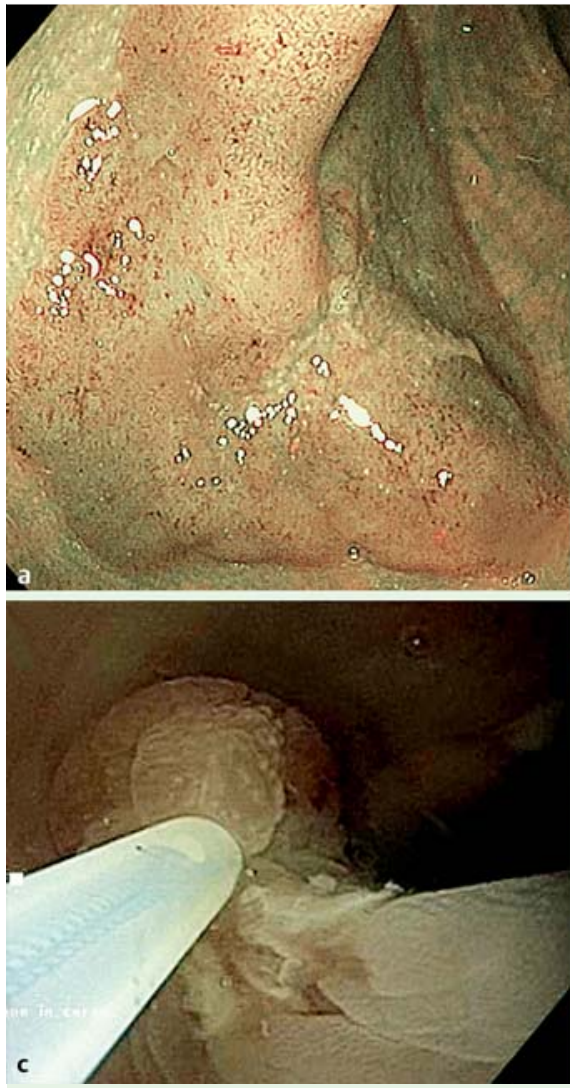

Fig. 1 a-d Endoscopic views during ClearPathassisted underwater endoscopic mucosal resection (EMR), showing: a appearance of colonic polyp using high-definition narrowband imaging;

A 50-year-old gentleman with a $4 \mathrm{~cm}$ laterally spreading tumor of the sigmoid colon was referred to our institute for endoscopic resection. Biopsy of this lesion confirmed the presence of an adenomatous polyp with high-grade dysplasia. Based on the size and histology of the polyp, and in view of its location in the sigmoid colon, we opted to carry out underwater endoscopic mucosal resection (UEMR) [1]. This procedure was carried out with a high-definition narrowband endoscope (GIF-H190; Olympus Medical, Center Valley, PA, USA) equipped with a ClearPath cleaning device (EasyGlide Ltd., Kfar Truman, Israel) to facilitate water irrigation and aspiration during the procedure. With the help of the ClearPath, the colon was rapidly irrigated with
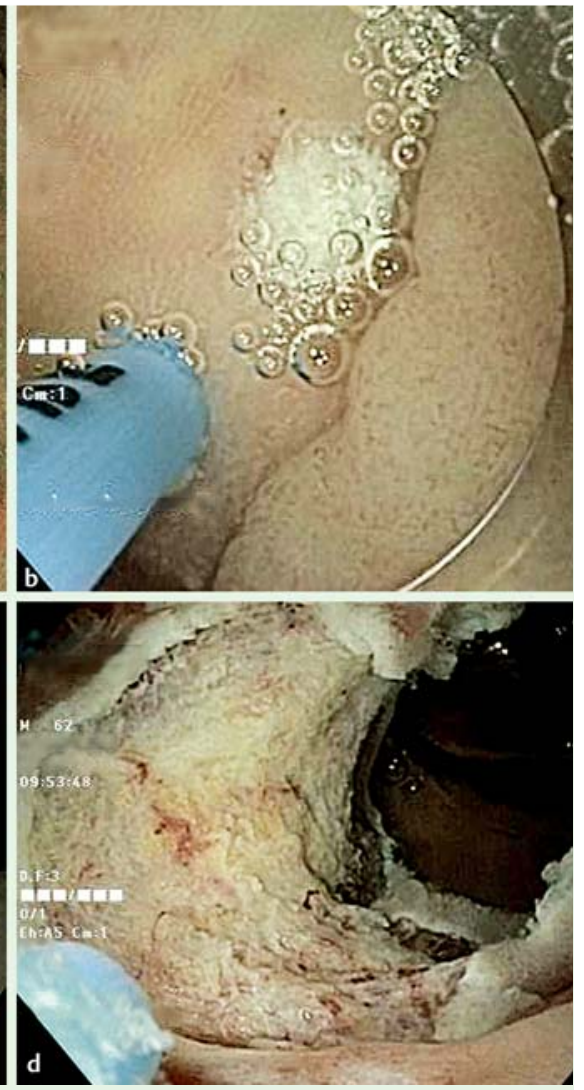

b underwater argon plasma coagulation marking of polyp margins; c piecemeal underwater EMR; d view after underwater EMR.

water, allowing piecemeal UEMR. All the polyp fragments, regardless of size, were aspirated through the ClearPath suction channel into the central suction canister $(\bullet$ Fig. 1, Fig. 2). The patient tolerated the procedure well with no adverse events recorded in the following days.

UEMR of large sessile colorectal polyps without submucosal injection was described by Binmoeller et al. in 2012 [1]. In their experience, 60 consecutive patients with large sessile colorectal polyps undergoing UEMR had successful complete resection and no early complications.

The ClearPath device has been developed for rapid luminal irrigation with high flow rates and efficient aspiration through its large suction channel ( Fig.2). This may allow evacuation of fluids, bile, and

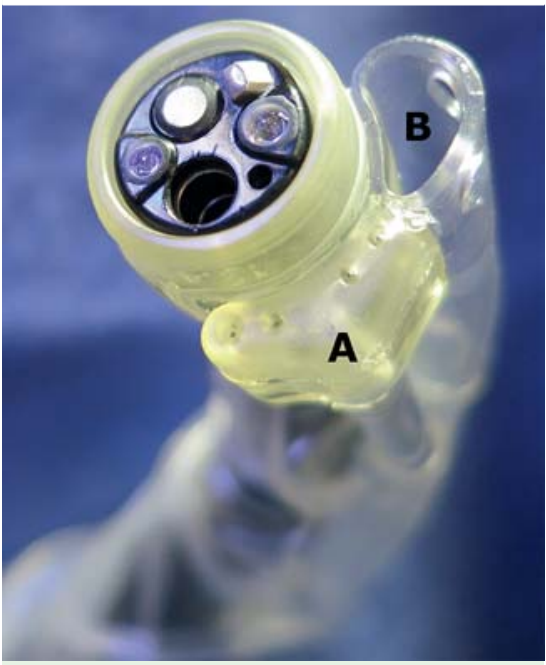

Fig. 2 Picture of the ClearPath device showing: a four irrigation nozzles; $\mathbf{b} 27 \mathrm{~mm}^{2}$ suction channel.

blood clots during upper gastrointestinal bleeding and has also been shown to be useful and safe for cleaning of poorly prepared porcine colon [2].

ClearPath-assisted underwater EMR allowed complete endoscopic resection while reducing procedure time due to fast colonic irrigation/aspiration and rapid polyp fragment retrieval. Although its efficacy cannot be fully demonstrated by a single report, this application of ClearPath appears useful and safe and may stimulate the development and manufacture of new, dedicated devices for UEMR.

Endoscopy_UCTN_Code_TTT_1AQ_2AD

Competing interests: None

\section{Gabriele Curcio, Antonino Granata, Neville Azzopardi, Patrizia Sanna, Luca Barresi, Ilaria Tarantino, Mario Traina}

Gastroenterology and Endoscopy Unit, Mediterranean Institute for Transplantation and Advanced Specialized Therapies (ISMETT), Palermo, Italy 


\section{References}

1 Binmoeller KF, Weilert F, Shah J et al. "Underwater" EMR without submucosal injection for large sessile colorectal polyps (with video). Gastrointest Endosc 2012; 75 : 1086-1091

2 Moshkowitz M, Hirsch Y, Carmel I et al. A novel device for rapid cleaning of poorly prepared colons. Endoscopy 2010; 42: $834-836$

\section{Bibliography}

DOI http://dx.doi.org/

10.1055/s-0033-1359127

Endoscopy 2014; 46: E40-E41

(C) Georg Thieme Verlag KC

Stuttgart · New York

ISSN 0013-726X
Corresponding author

Gabriele Curcio, MD

Gastroenterology and Endoscopy Unit ISMETT, UPMC

Via Tricomi 1

Palermo 90127

Italy

Fax: +39-091-2192400

gcurcio@ismett.edu 